\title{
PÓS-GRADUAÇÃO EM EDUCAÇÃO NO BRASIL E AS DEMANDAS PARA O V Plano NACIONAL DE Pós-Graduação*
}

Mariluce Bittar**

RESUMO

Neste artigo, analisa-se a pós-graduação em educação no Brasil, com ênfase nos desafios enfrentados pelos programas da região Centro-Oeste, no âmbito da reforma do Estado. Apresentam-se indicadores da pós-graduação brasileira que evidenciam a distribuição desigual entre as regiões do país. Esse movimento reproduz-se de forma significativa na área da educação, cujos dados indicam que, em relação ao número de bolsas do CNPq, por exemplo, as regiões Norte, Nordeste e Centro-Oeste são as que mais necessitam de auxílio; além disso, enfrentam dificuldades inclusive na atração e fixação de jovens doutores. Analisa-se também a política da Capes por meio dos programas nacionais de pós-graduação e os desafios colocados pela região Centro-Oeste no que diz respeito ao processo de avaliação na área da educação.

Palavras-chave: pós-graduação em educação, planos nacionais de pósgraduação, reforma do Estado.

\section{INTRODUÇÃO}

Neste artigo, analisa-se a pós-graduação em educação no Brasil, com ênfase nos desafios enfrentados pelos programas da região Centro-

\footnotetext{
* Artigo recebido em 5/4/2005 e aprovado em 25/5/2005.

** Doutora pela Universidade Federal de São Carlos (UFSCar); Coordenadora do Programa de Mestrado em Educação da Universidade Católica Dom Bosco; Coordenadora do Grupo de Estudos e Pesquisas sobre Educação Superior (Gepes) e, vice-presidente da Associação Nacional de Pós-Graduação e Pesquisa em Educação (Anped), gestão 2003-2005. E-mail: bittar@ucdb.br
} 
Oeste, no âmbito da reforma do Estado e da elaboração do novo Plano Nacional de Pós-Graduação.

Embora a análise delimite-se aos marcos da pós-graduação, é necessário lembrar, de acordo com Bernadete Gatti, que esse nível de ensino

não se coloca absolutamente à parte no sistema educacional. Pela nova LDB integra-se na educação superior e articula-se com os demais níveis, sendo seu papel delineado nas inter-relações e exigências propostas pela nova legislação da educação brasileira, mas, acima de tudo, pelo movimento histórico-social em que se insere [...]. O mundo científico tem a tendência de colocar mestrados e doutorados como instâncias à parte, como um olimpo. Porém, nada mais falso. Mestrados e doutorados são parte integrante do projeto educacional geral do país, e é nesse projeto que têm suas bases e suas articulações, e é assim que precisamos ser vistos e avaliados: como processos de educação. (1999, p. 35)

Concordando com as afirmações da autora e, tomando como base a proposta de reforma universitária em curso no governo de Luiz Inácio Lula da Silva, é preciso enfatizar que a análise da pós-graduação no Brasil deve estar articulada às políticas implementadas para a educação superior em seu conjunto. O quadro geral da educação superior brasileira demonstra uma inequívoca expansão do setor privado sob o setor público, pois praticamente $70 \%$ das matrículas dos estudantes desse nível de ensino está concentrada em instituições privadas, aí contempladas as particulares stricto sensu (aquelas declaradas com finalidade lucrativa) e as instituições comunitárias, filantrópicas e confessionais (aquelas declaradas sem finalidade lucrativa). O setor público, por sua vez, detém apenas $30 \%$ das matrículas e se subdivide em federais, estaduais e municipais, as segundas apresentando um expressivo movimento de expansão, sobretudo no que se refere ao processo de interiorização.

Com relação à pós-graduação em educação, os dados indicam que o setor público ainda é preponderante, porém há uma forte preocupação, por parte da comunidade acadêmica, com a expansão verificada na última década do século $\mathrm{XX}$, oriunda do setor privado.

Nesse sentido, é preciso situar claramente a preocupação de Bernadete Gatti, pois analisar a pós-graduação implica, necessariamente, refletir sobre o movimento que expressa as tendências atuais dos cursos de graduação no Brasil para que se possa, inclusive, desmistificar a idéia 
de que os programas de mestrado e doutorado estão à parte do processo de construção das políticas estatais para o ensino de graduação.

\section{CARACTERÍSTICAS DA PÓS-GRADUAÇÃO EM EDUCAÇÃO NO BRASIL}

Para se analisar a pós-graduação em educação no Brasil, é preciso situar a pós-graduação brasileira de acordo com alguns indicadores.

Segundo dados da Capes, divulgados no início de 2004, existem 1.931 programas de pós-graduação (mestrado e doutorado) no Brasil; a área de ciências humanas ocupa a segunda colocação na oferta de cursos, ou seja, 279 programas que equivale a $14,5 \%$ do total. A primeira posição pertence à área da saúde, com 375 programas, 19,4\% da totalidade da pós-graduação brasileira, o que explica, em parte, a predominância dessa ciência, de seus métodos e paradigmas sobre as demais áreas, especialmente nos critérios de avaliação da Capes. A área das ciências sociais aplicadas aparece em terceiro lugar (após a das ciências humanas), com a oferta de 224 cursos $(11,6 \%$ ), seguida das engenharias, com 217 cursos $(11,2 \%)$, e das ciências agrárias, 209 cursos $(10,8 \%)$ (CAPES, março de 2004). No que diz respeito à totalidade da pós-graduação brasileira, há que se destacar a sua distribuição de forma bastante desigual entre as regiões: 1.067 na região Sudeste $(55,26 \%)$; 375 na região Sul $(19,42 \%)$; 302 no Nordeste (15,64\%); 120 no Centro-Oeste $(6,21 \%)$ e 67 na região Norte $(3,47 \%)$. Registra-se, ainda, a existência de 80 programas profissionalizantes (www.capes.gov.br, acesso em março de 2004). O Quadro I sintetiza alguns indicadores importantes para a análise em questão.

Em relação ao número de alunos matriculados na pós-graduação, reproduz-se a mesma relação verificada na desigualdade regional, ou seja, existem 99.339 estudantes de pós-graduação no Brasil (61.383 em programas de mestrado, 34.801 em programas de doutorado e $3.155 \mathrm{em}$ mestrados profissionalizantes); desses, 67.919 estão vinculados à região Sudeste e correspondem a 68,37\% do total; 16.303, à região Sul (16,41\%); 9.460, ao Nordeste $(9,52 \%)$; 4.307, ao Centro-Oeste (4,34\%) e 1.350, à região Norte $(1,36 \%)$. A mesma distribuição entre as regiões pode ser verificada em relação aos docentes, pois dos 31.389 docentes vinculados à pós-graduação, 19.711 encontram-se em programas da região Sudeste (62,79\%); 5.522, na região Sul (17,59\%); 3.866, no Nordeste (12,32\%); 1.544 , no Centro-Oeste $(4,92 \%)$ e 746 , na região Norte $(2,38 \%)$ (Ibidem). 
102 BITTAR, M. - Pós-graduação em educação no Brasile as demandas...

QUADRO I

Número de Programas, Alunos e Docentes na

Pós-Graduação no Brasil, por Região (ano base 2002)

\begin{tabular}{|l|r|r|r|r|r|r|}
\hline \multirow{2}{*}{ Regiões } & \multicolumn{2}{|c|}{ Programas } & \multicolumn{2}{c|}{ Alunos } & \multicolumn{2}{c|}{ Docentes } \\
\cline { 2 - 7 } & \multicolumn{1}{|c}{$\mathrm{N}^{\mathrm{o}}$} & \multicolumn{1}{c|}{$\%$} & \multicolumn{1}{c|}{$\mathrm{N}^{\mathrm{o}}$} & \multicolumn{1}{c|}{$\%$} & \multicolumn{1}{c|}{$\mathrm{N}^{\mathrm{o}}$} & \multicolumn{1}{c|}{$\%$} \\
\hline SUDESTE & 1067 & $55,26 \%$ & 67919 & $38,37 \%$ & 19711 & $62,79 \%$ \\
\hline SUL & 375 & $19,42 \%$ & 16303 & $16,41 \%$ & 5522 & $17,59 \%$ \\
\hline NORDESTE & 302 & $15,64 \%$ & 9460 & $9,52 \%$ & 3866 & $12,32 \%$ \\
\hline CENTRO-OESTE & 120 & $6,21 \%$ & 4307 & $4,34 \%$ & 1544 & $4,92 \%$ \\
\hline NORTE & 67 & $3,47 \%$ & 1350 & $1,36 \%$ & 764 & $2,38 \%$ \\
\hline BRASIL & 1931 & $100 \%$ & 99339 & $100 \%$ & 31389 & $100 \%$ \\
\hline
\end{tabular}

FONTE: http://www.capes.gov.br, março de 2004

No que diz respeito à área das ciências humanas, compostas por 279 programas, a hegemonia na oferta pertence à educação, com 73 programas, ou $26,1 \%$ do total. Logo em seguida, está posicionada a psicologia, com 46 programas (16,5\%), a sociologia que oferece 35 cursos $(12,5 \%)$ e a história, com 33 cursos (11,8\%). Em seguida, estão colocadas as seguintes áreas: geografia (29 cursos), filosofia (27), ciência política (13), antropologia (12), teologia (10) e, finalmente, a arqueologia, com um programa de pós-graduação.

Com relação aos programas de pós-graduação em educação, o Quadro II demonstra três indicadores fundamentais:

QUADRO II

Número de Programas, Alunos e Docentes na Pós-Graduação em Educação no Brasil, por Região (ano base 2002)

\begin{tabular}{|l|r|r|r|r|r|r|}
\hline \multirow{2}{*}{ Regiões } & \multicolumn{2}{|c|}{ Programas } & \multicolumn{2}{c|}{ Alunos } & \multicolumn{2}{c|}{ Docentes } \\
\cline { 2 - 7 } & \multicolumn{1}{|c}{$\mathrm{N}^{\mathrm{o}}$} & \multicolumn{1}{c|}{$\%$} & \multicolumn{1}{c|}{$\mathrm{N}^{\mathrm{o}}$} & \multicolumn{1}{c|}{$\%$} & \multicolumn{1}{c|}{$\mathrm{N}^{\mathrm{o}}$} & \multicolumn{1}{c|}{$\%$} \\
\hline SUDESTE & 35 & $47,94 \%$ & 1958 & $48,88 \%$ & 661 & $47,86 \%$ \\
\hline SUL & 18 & $24,66 \%$ & 970 & $24,21 \%$ & 351 & $25,42 \%$ \\
\hline NORDESTE & 11 & 15,07 & 569 & $14,20 \%$ & 220 & $15,93 \%$ \\
\hline CENTRO-OESTE & 7 & $9,59 \%$ & 459 & $11,46 \%$ & 131 & $9,49 \%$ \\
\hline NORTE & 2 & $2,74 \%$ & 50 & $1,25 \%$ & 18 & $1,3 \%$ \\
\hline BRASIL & 73 & $100 \%$ & 4006 & $100 \%$ & 1381 & $100 \%$ \\
\hline
\end{tabular}

FONTE: http://www.capes.gov.br, março de 2004 
De acordo com os dados apresentados, existem 73 programas recomendados pela Capes; desses, 33 localizam-se na região Sudeste (45,2\%), 18, no Sul (24,6\%), 11, no Nordeste (15\%), 9, no Centro-Oeste $(12,3 \%)$ e apenas 2 , na região Norte $(2,7 \%)$, indicando a reprodução da mesma desigualdade regional verificada na pós-graduação de modo geral (Ibidem).

Pode-se observar que, do total de alunos matriculados em programas de pós-graduação em educação, a maior concentração encontra-se na região Sudeste, com aproximadamente 50\% de matrículas; os outros $50 \%$ distribuem-se, de forma desigual, entre as regiões Sul, com 24\%, Nordeste, com 14\%, Centro-Oeste, com $11 \%$, e Norte, com 1,2\%. A distribuição geográfica revela a desigualdade da produção científica no Brasil, no que se refere aos programas de modo geral e, em específico, à área da educação. De certo modo, os números indicam que, de forma quase perversa, as dificuldades regionais para a consolidação da pesquisa e da pós-graduação "obedecem" a critérios também perversos no financiamento e na avaliação da pós-graduação, cuja tendência é privilegiar os centros de excelência e os programas já consolidados, os quais se concentram nas regiões Sul e Sudeste.

Esta parece ser a lógica presente nos critérios de oferta de bolsas para a pós-graduação. Segundo informações do presidente do CNPq, em fevereiro de 2004, o número de bolsas para os programas de mestrado e doutorado totalizava 12.315 (CAMARGo, março de 2004). Desse total, apenas 186 bolsas foram destinadas para a área da educação, distribuídas entre as regiões, da seguinte forma:

QUADRO III

Relação de Cotas - Bolsas CNPq

\begin{tabular}{|l|c|c|}
\hline \multicolumn{2}{|c|}{ MESTRADOS/DOUTORADOS EM EDUCAÇÃO } \\
\hline \multicolumn{1}{|c|}{ Regiões } & $\%$ & Total \\
\hline SUDESTE & $73,66 \%$ & 137 \\
\hline SUL & $24,20 \%$ & 45 \\
\hline NORDESTE & $1,07 \%$ & 2 \\
\hline CENTRO-OESTE & $1,07 \%$ & 2 \\
\hline NORTE & 0 & 0 \\
\hline TOTAL GERAL & $100 \%$ & 186 \\
\hline
\end{tabular}

FONTE: CNPq, março/2004. 
De acordo com os dados, reproduz-se a hegemonia das regiões Sudeste e Sul sob as demais regiões do Brasil. Nota-se que, no caso das bolsas, há uma distribuição mais grave e perversa, já que as regiões Nordeste e Centro-Oeste possuem apenas quatro bolsas do total, enquanto a região Norte não obteve nenhuma cota. Diante desse quadro, é preciso indagar como enfrentar os desafios da consolidação dos programas nessas regiões mais carentes de recursos humanos e tecnológicos se o Estado não tem uma política clara de incentivo financeiro para eles? Prova dessa inquietação são os recursos destinados para a pesquisa, pois o Ministério da Ciência e Tecnologia recuou em sua proposta de descentralização de recursos, priorizando os chamados "centros de excelência"; desse modo, as regiões Sudeste e Sul continuam detendo aproximadamente $80 \%$ dos recursos, ao passo que as regiões Nordeste, Centro-Oeste e Norte receberam apenas $12 \%, 6,7 \%$ e 3,1\%, respectivamente (FolHA DE S. PAUlo, março de 2004). Outro dado relevante de ser analisado refere-se ao financiamento de projetos de pesquisa: de acordo com os resultados divulgados pelo CNPq, do Edital Universal das Ciências Humanas e Sociais, de junho de 2003, a região Sudeste recebeu $50 \%$ do financiamento, a região Sul, 32,5\%, as regiões Nordeste e Norte ficaram com $15 \%$ e $2,5 \%$, respectivamente, e a região Centro-Oeste não recebeu nenhum financiamento (http://www.cnpq.br, maio de 2004). Acrescem-se a esses fatores a dificuldade que os programas das regiões Norte-Nordeste e Centro-Oeste têm em atrair e fixar jovens doutores, já que a grande maioria desses novos pesquisadores conclui seus cursos de doutorado em centros consolidados de pesquisa, em universidades que já possuem grupos de pesquisa instalados e produção científica reconhecida pelos pares, portanto, não se sentem estimulados a se fixarem em centros considerados "periféricos" e que não recebem os mesmos incentivos financeiros das políticas governamentais. Esse fenômeno pode ser verificado tanto em programas de universidades privadas quanto de universidades públicas, pois ambos os setores têm dificuldades em contratar jovens pesquisadores.

Com relação à distribuição entre os setores público e privado, do total de 73 programas, 41 estão vinculados às instituições públicas, representando 56,2\%, e, no setor privado, funcionam 32 programas, significando 43,8\%. O Quadro IV apresenta esses indicadores: 
QUADRO IV

Pós-Graduação em Educação - Natureza Jurídica (ano base 2002)

\begin{tabular}{|l|c|c|}
\hline \multicolumn{1}{|c|}{ Nature za Jurídica } & Total & $\%$ \\
\hline Pública & 42 & $57,53 \%$ \\
\hline Federal & 29 & $39,72 \%$ \\
\hline Estadual & 13 & $17,81 \%$ \\
\hline Municipal & - & - \\
\hline Privada & 31 & $42,47 \%$ \\
\hline Particular & 11 & $15,07 \%$ \\
\hline Comunitária/Confessional/Filantrópica & 20 & $27,40 \%$ \\
\hline Total Geral & 73 & $100 \%$ \\
\hline
\end{tabular}

FONTE: http://www.capes.gov.br, março de 2004.

Como se pode observar, inversamente ao que ocorre no ensino de graduação, em que $70 \%$ das matrículas está vinculada ao setor privado e, de modo preponderante, na iniciativa privada empresarial, na pósgraduação é o setor público que concentra o maior número de programas, praticamente $58 \%$ do total. Nota-se, também, um expressivo número de programas nas instituições estaduais, revelando um movimento crescente de abertura de programas nessas universidades, que possuem campi em diversas cidades do interior dos estados da federação, constituindo-se em alternativa de ensino público para os candidatos afastados das oportunidades dos grandes centros. Quanto à iniciativa privada, os dados revelam a preponderância do segmento comunitário/confessional/ filantrópico sob as instituições particulares stricto sensu, ou seja, aquelas que se autodeclaram com finalidade lucrativa. É preciso ressaltar a forte pressão por abertura de novos programas por parte desse setor educacional, movimento intensificado nos últimos anos da década de 1990, o qual deve ser foco de preocupação por parte das comissões de avaliação da Capes.

POLÍTICA DE PÓS-GRADUAÇÃO DA CAPES EXPRESSA NOS PLANOS NACIONAIS DE PÓS-GRADUAÇão

O I Plano Nacional de Pós-Graduação (I PNPG), aprovado pela CAPES em 1975, vigente durante os anos do regime militar e aprovado 
sob os auspícios do governo do general-presidente Ernesto Geisel, estava previsto para ser desenvolvido no período de cinco anos, porém perdurou até 1982, quando foi aprovado o II Plano, já no governo do generalpresidente João Baptista Figueiredo, que deu continuidade ao seu predecessor.

Os objetivos explícitos no I Plano estavam concentrados em torno do diagnóstico da pós-graduação, análise do processo de crescimento e construção de indicadores necessários à expansão do sistema. $\mathrm{O}$ documento informava que a pós-graduação no Brasil, desde o seu início, havia formado, até então, 3.500 mestres e 500 doutores e previa como meta, para o quinquênio 1975/1979, a titulação de "16.800 mestres e 1.400 doutores", além de ampliar "a capacidade de atendimento dos cursos de pós-graduação no país, passando de 7.000 para cerca de 11.700 vagas anuais de mestrado, e de 500 para cerca de 1.200 vagas anuais de doutorado" (I Plano Nacional de Pós-Graduação, 1996, p. 38). As justificativas para tal ampliação respaldavam-se nas "transformações ocorridas em nosso país nas últimas décadas, notadamente a urbanização e a industrialização", as quais exigiam "novas profissões e especialidades". Além disso, apontava a necessidade de estimular a "produção científica própria e regular" dos pesquisadores brasileiros que estavam vinculados aos "poucos núcleos de produção científica, isolados entre si, com poucos recursos e sem programas orientadores" (I PNPG, 1998, p.15). Delineavase, com base nesse diagnóstico, o objetivo principal do I Plano Nacional de Pós-Graduação, que consistia em

transformar as universidades em verdadeiros centros de atividades criativas permanentes, o que será alcançado na medida em que o sistema de pós-graduação exerça eficientemente suas funções formativas e pratique um trabalho constante de investigação e análise em todos os campos e temas de conhecimento humano e da cultura brasileira. (1998, p.17)

O II PNPG, aprovado para o período 1982-1985, mantinha como objetivo central "a formação de recursos humanos qualificados para as atividades docentes, de pesquisa em todas as suas modalidades e técnicas, para o atendimento às demandas dos setores público e privado" (II PNPG, 1998, p. 21). Enquanto o I Plano apresentava tabelas quantitativas sobre a realidade da pós-graduação no início da década de 1970 e as estimativas 
numéricas de expansão para os próximos anos, o II Plano trazia mais explicitamente a preocupação com a "qualidade, manifestada seja nos profissionais formados, seja nas pesquisas realizadas". Para acompanhar a qualidade do sistema, acenava-se para a necessidade de se criarem "estímulos e condições favoráveis" para o "aumento qualitativo" dos programas de pós-graduação, "acionando mecanismos de acompanhamento e avaliação" (II PNPG, 1998, p. 25). Para justificar o processo de avaliação, o plano explicitava que a "exigência da qualidade" provinha de três indicadores: "o mercado, a própria comunidade científica, e as instituições governamentais com poder político-normativo ou detentoras de recursos de financiamento" (p. 23); desse modo, a avaliação deveria ser um processo a ser implementado para garantir a qualidade dos programas de pós-graduação, levando em consideração "o mérito do pedido e os resultados finais esperados" (p. 26).

No I PNPG, percebia-se a preocupação da Capes com o atendimento da demanda educacional, isto é, formar pesquisadores que pudessem fornecer o suporte necessário ao crescimento dos programas de pós-graduação em todo o país. No II PNPG, a perspectiva assumida pela agência foi a de uma formação mais abrangente, para atender aos interesses do setor produtivo. Na avaliação desses planos, a Capes destacava "duas grandes conquistas" para o sistema nacional de pósgraduação brasileiro:

aumento da absorção de pessoal em regime de tempo integral e dedicação exclusiva dos professores nas redes federais e a implantação do Programa Institucional de Capacitação Docente (PICDT). Foi também considerado de extrema relevância o desenvolvimento e a consolidação do Sistema de Acompanhamento e Avaliação da PósGraduação sob sua responsabilidade. (III Plano Nacional de PósGRADUAÇÃo, 1998, p. 23)

Essas considerações faziam parte da introdução do III Plano Nacional de Pós-Graduação que, em tese, deveria reger os princípios da pós-graduação no Brasil, no período de 1986 a 1989. Entre os problemas apontados na avaliação do I e II PNPG, foi indicado, entre outros, o financiamento dos programas de pós-graduação, pois as atividades a eles inerentes são dependentes de recursos extra-orçamentários, estando sujeitos a cortes e atrasos na alocação e liberação de verbas. Além disso, são constantemente atingidos "pelas percepções imediatistas das 
políticas governamentais refletidas nas freqüentes mudanças de prioridades" (III PNPG, 1998, p. 27).

Registrava-se ainda ausência de política de apoio aos grupos emergentes e de desenvolvimento científico regional, a exemplo das universidades do Norte do Brasil, sobretudo as da região amazônica que, uma vez afastadas dos grandes centros culturais e científicos (Sul e Sudeste) do país, ressentiam-se de apoio efetivo das agências financiadoras, fato que gerou destaque no plano estratégico do III PNPG, visando "ampliar substancialmente o apoio para a formação de recursos humanos e para o desenvolvimento científico da região amazônica" (III PNPG, 1998, p. 34). A tônica do III PNPG recaía sobre a necessidade de continuarse investindo na formação de recursos humanos para a ciência e a tecnologia, pois se admitia que o país não possuía número suficiente de cientistas que pudesse responder às exigências de, em um futuro próximo, atingir a "independência econômica, científica e tecnológica para o Brasil" (p. 23).

O III Plano Nacional de Pós-Graduação (1998) apresentava os seguintes objetivos:

1) consolidação e melhoria do desempenho dos cursos de pósgraduação;

2) institucionalização da pesquisa nas universidades para assegurar o funcionamento da pós-graduação;

3) integração da pós-graduação ao sistema de ciência e tecnologia, inclusive com o setor produtivo (p. 24).

As diretrizes definidas no III PNPG deveriam desenvolver-se num período de quatro anos - de 1986 a 1989 -, quando passaria a vigorar o IV Plano Nacional de Pós-Graduação. Este, no entanto, não chegou a ser elaborado durante toda a década seguinte até os dias atuais, embora tenham sido publicados, no boletim Infocapes, vários artigos e documentos oriundos de seminários sobre a pós-graduação brasileira, apontando a necessidade de um novo plano que definisse a política para o setor. Destaca-se, entre esses, o documento intitulado "Pós-Graduação: enfrentando novos desafios", oriundo do seminário nacional promovido pela Capes em maio de 2001. Ao reunir representantes da comunidade acadêmica nacional, a Capes tinha por objetivo refletir sobre as "lacunas da pós-graduação nacional”. Na apresentação do referido documento, o 
então presidente da Capes, Abilio Baeta Neves (2001), considerou que os

dados existentes atestam de forma inequívoca que a pós-graduação brasileira cresceu de forma significativa nos últimos trinta anos. Ela adquiriu uma dimensão imponente no conjunto do sistema de ensino superior do país e não seria incorreto afirmar que constitui atualmente o melhor capítulo da política de ensino superior nas últimas décadas (Pós-GRAdUAÇÃo ENFRENTANDO NOVOS DESAFIOS, 2001, p. 5).

Algumas das principais "lacunas" apontadas no documento são: 1) inexistência do IV Plano Nacional de Pós-Graduação e Pesquisa e de "uma adequada política de governo para a educação superior no país"; 2) perda de quadros atuantes na pós-graduação, devido à ausência de política salarial; 3) insuficiência de infra-estrutura, acervos e recursos para custeio, destacando-se a criação dos Fundos Setoriais e da necessária "vinculação entre os programas de pós-graduação e os projetos apoiados pelos diferentes Fundos, para que o investimento permita a expansão da base científica nacional" e 4) "desequilíbrio, tanto em termos regionais como intra-regionais (capitais versus interior) e em termos de subáreas temáticas" (Pós-GRADUAÇão ENFRENTANDO NOVOS DESAFIOS, 2001, p. 7-11).

Além desses tópicos, identifica-se nos três planos nacionais de pós-graduação a preocupação com o tempo de titulação, principalmente no que se refere ao tempo despendido para a realização do mestrado. Nesse caso, percebe-se o apoio aos mestrados interdisciplinares e aos profissionalizantes e à "desaceleração dos mestrados acadêmicos", que seriam, de certa forma, substituídos pelo incentivo aos programas de iniciação científica, estimulando a "entrada direta no doutorado ou a passagem mais rápida para este nível, nas áreas do conhecimento em que tal ação seja adequada" (Pós-GRADUAÇão ENFRENTANDO NOVOS DESAFIOS, 2001, p. 12-14). Outras ações, como, por exemplo, "flexibilização do sistema", "dos currículos e dos programas" e "otimização da capacidade instalada" aparecem nos documentos como questões a serem debatidas com mais profundidade pela comunidade acadêmica. Aponta-se, ainda, para a "necessidade de formar profissionais voltados para o futuro", portanto, as instituições de ensino e as agências de fomento devem preocupar-se com a introdução de "questões como empreendedorismo, gestão, educação continuada e ensino a distância" (Pós-GRADUAÇão ENFRENTANDO NOVOS DESAFIOS, 2001, p. 12). 
Ainda sobre a questão dos planos nacionais de pós-graduação, é importante registrar que o governo de Luiz Inácio Lula da Silva, no âmbito das medidas que constituem as propostas de reforma universitária, compôs comissão mista Capes/CNPq para o Desenvolvimento da Pós-Graduação e da Ciência e Tecnologia que, por sua vez, elaborou documento denominado "Considerações preliminares para o V PNPG". Nesse documento, a comissão considera a existência de um IV Plano Nacional de Pós-Graduação (vigente de 1998 a 2002), mas afirma a "ausência" de sua "oficialização" baseada no fato de que "seu resultado não parece ter sido assimilado como uma definição de políticas de governo em relação à pós-graduação brasileira" (Comissão MISTA CAPES/CNPQ, 2004, p. 8). O referido documento aponta, também, as questões que precisariam ser refletidas por aqueles que militam nesse setor educacional, visando à elaboração do V PNPG, quais sejam: flexibilidade, expansão, regionalização, interdisciplinaridade, legitimidade social e internacionalização. No que diz respeito à regionalização, a comissão afirma o seguinte:

O sistema de pós-graduação é nacional, e, por isso mesmo, deve contemplar diferenças e especificidades regionais. Por ser pouco flexível, o sistema deixa de adaptar-se à diversidade de realidades, exigências e possibilidades regionais. Por ter uma dificuldade histórica de operar com as diferenças, termina por aprofundar as desigualdades, ao tratar univocamente realidades distintas. (Ibid., p. 17)

Em maio de 2004, por meio da Portaria n. 046, de 19 de maio de 2004, a Capes instituiu a "Comissão responsável pela elaboração do Plano Nacional de Pós-Graduação - PNPG, relativo ao qüinquiênio 2005-2010”. Para cumprir com a tarefa solicitada pela presidência da Capes, a comissão solicitou da comunidade acadêmica sugestões sobre vários temas. Entre eles, aparece novamente a preocupação com a regionalização, no sentido de enfrentar as "assimetrias regionais"; a identificação de áreas prioritárias; as debilidades, potencialidades e oportunidades do sistema de pós-graduação e o financiamento da pós-graduação. Percebe-se, tanto no documento da comissão mista, instituída em 2003, quanto na comissão indicada pela Capes, em 2004, a indicação de temas cruciais que devem ser enfrentados pela pós-graduação brasileira e que devem afetar, de modo significativo, as ciências humanas, pois a produção da pesquisa das áreas que compõem as humanidades não segue o mesmo paradigma de produção de pesquisa das ciências exatas e das ciências biológicas. 
Nessa perspectiva, a proposta da Associação Nacional de Pós-Graduação e Pesquisa em Educação (Anped), assim se manifesta:

No que diz respeito à pós-graduação na área de Educação, afirma-se a institucionalização da pesquisa nesse campo de conhecimento, como essencialmente humanitário e social. Seu objeto central de estudo é o fenômeno educativo, nas mais distintas formas e dimensões em que socialmente se manifesta. Os estudos pós-graduados em Educação formam especialmente docentes e pesquisadores para as Instituições de Ensino Superior (IES) do país. São eles os docentes/pesquisadores com formação específica na área, que sustentam a produção científica, promovem e fazem avançar este campo de conhecimento. Tal é a natureza do perfil epistemológico da área. Como se sabe, possuir especificidade e perfil epistemológico próprio são requisitos indispensáveis à constituição de uma área de conhecimento científico, entendimento este presente nas instituições que tratam de ciência e de tecnologia - em seu planejamento, avaliação e fomento - como é o caso da Capes. (ANPED, jul. 2004, p. 3)

Além dessas preocupações, há que se levar em consideração, na elaboração de um novo Plano Nacional de Pós-Graduação, a sistemática de avaliação adotada pela Capes. Sem desconsiderar a consolidação e o reconhecimento da importância dos processos de avaliação instituídos pelas políticas educacionais implementadas pela Capes, é preciso reposicionar o papel da avaliação, especialmente quando os critérios estabelecidos tendem a avaliar como igual o que é extremamente desigual, a exemplo dos programas das instituições universitárias nas quais a pesquisa encontra-se em processo de consolidação.

\section{AvaLIAÇÃO DA PÓS-GRADUAÇÃO EM EDUCAÇÃO}

De acordo com Bernadete Gatti, algumas questões devem ser refletidas quando se analisam as características referentes ao sistema de avaliação da Capes para a área da educação e que, de acordo com os dados apresentados nos itens anteriores, devem fazer parte da pauta de preocupações dos formuladores dessa política, já que a avaliação, embora reconhecidamente seja um processo consolidado no âmbito da Capes e do próprio $\mathrm{MEC}$, tende a reproduzir as mesmas desigualdades regionais verificadas nos dados já apresentados. 
112 BITTAR, M. - Pós-graduação em educação no Brasile as demandas...

Para a autora:

a) adotar critérios de avaliações gerais de países com tradições e condições históricas totalmente diferentes das nossas é válido? Até que ponto? Qual a validade e fidedignidade podemos atribuir a uma avaliação com essas características? Que valor social tem?

b) quais são os reais pressupostos que sustentam os procedimentos de avaliação adotados e as políticas que geram? Respondem ao interesse público ou a certos grupos de poder? Quais? (1999, p. 45)

Essas reflexões vêm ao encontro de questionamentos feitos pelo Fórum de Coordenadores de Programas de Pós-Graduação em Educação da Região Centro-Oeste ${ }^{1}$ que, em fevereiro de 2003, elaborou documento com o fito de contribuir com as discussões desencadeadas pelo Fórum Nacional de Coordenadores de Programas de Pós-Graduação em Educação, no âmbito da Anped, que visavam à elaboração de uma proposta alternativa de avaliação da pós-graduação em educação. Naquela ocasião, os coordenadores afirmaram o seguinte:

o modelo de avaliação em vigor apresenta certos aspectos que vêm suscitando dúvidas e dificuldades. A ausência, há décadas, de uma política de pós-graduação no Brasil vem gerando insatisfação na comunidade acadêmica. [...] Em linhas gerais o discurso oficial veiculado propõe a melhoria da eficiência dos programas de pósgraduação em funcionamento. Também propõe critérios mínimos para funcionamento dos que solicitam autorização, na tentativa de conter a expansão de propostas de pós-graduação em instituições que não possuem áreas de pesquisa minimamente fortalecidas. Entretanto, a consolidação e melhoria da eficiência dos programas têm enfrentado, além das dificuldades contextuais e particulares de cada IES, aquelas pertinentes a um sistema avaliativo que por vezes imobiliza as ações desses mesmos programas. Tal sistema tem assumido um caráter bem menos colaborativo do que punitivo, sobretudo por não levar em conta as peculiaridades de cada região, instituições de grupos de trabalho. (EDUFOCo, fev. 2003)

De acordo com o documento, os coordenadores expressavam, naquela ocasião, as dificuldades e as exigências impostas pelo atual modelo de avaliação que, de certa forma, adota critérios homogêneos para todos os programas, tendo como parâmetro de excelência e 
produtividade os programas historicamente já consolidados e que concentram maior número de pesquisadores, de grupos de pesquisa cadastrados no diretório do CNPq, de bolsas para mestrandos e doutorandos, entre outros. Além de questionarem as implicações da adoção dos critérios comuns a todos, para os programas recém-criados e com dificuldades inerentes à região em que se inserem, os coordenadores também apontavam para a necessidade de "definição de uma política de pós-graduação em educação, que explicite o sistema de avaliação, bem como o seu modelo teórico", pois essas seriam as condições primordiais para que "os critérios, os indicadores e os parâmetros" utilizados por um sistema de avaliação possam ser justificados e aceitos pela área. Continuam os coordenadores afirmando que, "Sem ter como seguir uma direção educacional segura da Capes/MEC, é questionável a fundamentação de certas críticas e sugestões das comissões para corrigir supostos desvios dos programas", ao mesmo tempo em que esse procedimento procuraria "garantir coerência interna da Comissão de Avaliação da Área da Educação da Capes".

O documento, apresentado pelo Fórum de Coordenadores do Centro-Oeste, baseava-se em quatro perguntas fundamentais:

a) Que tipo de pós-graduação em educação pode ser adequado e desejável para o país, no atual momento histórico?

b) Qual o projeto político do atual governo proposto para a pósgraduação em educação?

c) Quais seriam as diretrizes e prioridades a serem estabelecidas num possível plano de pós-graduação?

d) Quais seriam as estratégias para a sua execução? (Edufoco, fev. 2003)

Após análise das dificuldades enfrentadas pelos programas da região, o fórum apresenta as seguintes proposições que deveriam estar presentes em um novo modelo de avaliação:

a) valorizar o esforço de cada programa na construção de sua identidade com base em sua matriz curricular, linhas de pesquisa, produção científica e outros indicadores;

b) respeitar a trajetória histórica e as características de cada programa, no que se refere a seu papel social e objetivos, avaliando-o na sua 
totalidade sem reduzi-lo a um conjunto de dados quantitativos mensurados em índices;

c) rever os procedimentos adotados na avaliação continuada de forma que sejam ampliadas as modalidades de comunicação com os programas, garantindo interlocução entre o corpo docente do programa e a comissão de avaliação da Capes;

d) romper com o modelo comparativo entre Programas de PósGraduação, eliminando o caráter classificatório e punitivo do atual modelo avaliativo. (EDufoco, fev. 2003)

As necessidades e as reivindicações expressas pelos programas de pós-graduação em educação da região Centro-Oeste estão contempladas no documento mais amplo, elaborado posteriormente pelo grupo gestor indicado pelo Fórum Nacional de Coordenadores de Programas de Pós-Graduação em Educação (Eduforum), para congregar as propostas dos fóruns regionais sobre a avaliação da pós-graduação. Intitulado "Por um modelo alternativo de avaliação da pós-graduação nacional", o referido documento enfatiza a necessidade de que a "política de avaliação se diferencie da política de fomento e que se enfatize mais a qualidade do que a quantidade [...]". Além disso, a proposta de um modelo alternativo de avaliação, para o grupo gestor, deve

garantir adequada articulação ente os elementos qualitativos e as referenciações quantitativas, sua efetiva execução por pares legitimados, escolhidos de forma efetivamente representativa, o reconhecimento das especificidades da área da educação e das ciências humanas, em geral, em relação às demais áreas bem como as peculiaridades dos programas, decorrentes de suas condições históricas, respeitadas as suas diferenças. (2002, p. 1)

São grandes os desafios impostos à pós-graduação brasileira, e um deles, sem dúvida, ao modelo vigente de avaliação e às especificidades regionais e de produção científica de cada programa. Deve-se levar em consideração o papel social que os programas assumem no interior do Brasil, no fomento à produção científica e ao desenvolvimento da ciência e da tecnologia. Para isso, há a necessidade de se rever a concepção de programas de mestrado da própria Capes, vez que se anuncia, em documentos oficiais, uma tendência a encarar esse nível da pós-graduação apenas como uma etapa para se atingir o doutorado. Nessa perspectiva 
é que concorrem as políticas de flexibilização da pós-graduação, no sentido de diminuir cada vez mais o tempo de realização do mestrado e torná-lo mais integrado às exigências do mercado, tendência essa presente em vários documentos sobre a pós-graduação no Brasil, já citados neste texto.

Por fim, há muito para ser aprofundado nessa temática, sobretudo se se levar em consideração os propósitos da reforma do Estado, a qual preconiza a diminuição da responsabilidade estatal na garantia das políticas sociais, entre elas a da educação. A pós-graduação, por extensão, estaria sujeita às imposições do mercado (que determinaria, inclusive, quais áreas seriam e serão beneficiadas com financiamentos públicos) e às exigências do neoliberalismo, no que se refere à inserção do Brasil no mundo globalizado. É claro que, nesse caso, as ciências exatas e as ciências biológicas, tidas como aquelas que oferecem resultados imediatos às necessidades do mercado consumidor, estariam contempladas no âmbito das referidas reformas. O mesmo não se pode dizer em relação às ciências humanas, em especial, a área da educação, já que a esta nem sempre é possível exigir resultados práticos e imediatos, pois os processos educacionais de formação da cidadania podem exigir anos ou décadas de investimentos de um país, cujos reflexos no desenvolvimento qualitativo da sociedade apenas as futuras gerações poderão plenamente desfrutar.

\section{ABSTRACT}

In this article, Brazilian post-graduate studies in education are analyzed, with emphasis on the challenges faced by programmes in the mid-western region, within the sphere of State reform. Indicators of Brazilian post-graduate studies are presented, showing the unequal distribution between the different regions of the country. This phenomenon is significantly reproduced in the area of education, the data of which would indicate that, in relation to the number of CNPq government scholarships, for example, the north, northwest and mid-west are most in need of help; in addition, these regions even face difficulties in attracting and keeping young PhDs. The government's CAPES policy is also analyzed through National Post-Graduate Study Programmes, as are the challenges faced by the mid-western region in regard to the process of evaluation in the field of education.

Key words: Post-Graduate Studies in Education; National Post-Graduate Study Plans; State Reform. 


\section{NOTAS}

Este artigo, originariamente intitulado "Pós-graduação em educação (financiamento, expansão, avaliação), a partir das exigências da região, no contexto da reforma universitária", foi apresentado no VII Epeco - Encontro de Pesquisa em Educação do Centro-Oeste (Anped - Centro-Oeste), realizado em Goiânia de 9 a 11 de junho de 2004 e promovido pelo Fórum de Coordenadores de Programas de Pós-Graduação em Educação da Região Centro-Oeste. Para a publicação neste periódico foram acrescentadas informações e análises que não puderam ser aprofundadas naquela ocasião.

1. Integram a região Centro-Oeste os seguintes programas: Universidade Católica Dom Bosco (UCDB), Universidade Federal de Mato Grosso do Sul (UFMS), Universidade de Brasília (UnB), Universidade Católica de Brasília (UCB), Universidade Federal de Goiás (UFG), Universidade Católica de Goiás (UCG), Universidade Federal de Mato Grosso (UFMT), Universidade de Cuiabá (UNIC), Universidade Federal de Uberlândia (UFU), Centro Universitário do Triângulo (Unitri) e Universidade de Uberaba (Uniube).

\section{REFERÊNCIAS}

ANPEd. V Plano Nacional de Pós-Graduação - subsídios apresentados pela Anped. Rio de Janeiro, jul. 2004.

BITTAR, M.; VELOSO, T. C. M. A.; SILVA, M. das G. M. da. Infocapes: A pósgraduação como eixo de análise. 2002. Texto a ser publicado na 27a Reunião Anual da Anped, em novembro de 2004, Editora Cortez.

CAMARGO, E. P. de. Ofício PR. n. 0111/04, encaminhado aos coordenadores de programas de pós-graduação do Brasil. Brasília: CNPq, 25 mar. 2004.

CAPES. Portaria n. 046, 19 maio 2004. Disponível em: 〈http://www.capes.gov.br〉.

COMISSÃO Mista Capes/CNPq para o Desenvolvimento da Pós-Graduação e da Ciência e Tecnologia. Plano nacional de pós-graduação - considerações preliminares para o V PNPG. Brasília: Portaria Interministerial MCT/MEC, n. 270, 22 maio 2003, jan. 2004.

EDUFOCO. Reflexões sobre o modelo de avaliação da pós-graduação em educação. Contribuições do Fórum de Coordenadores de Programas de PósGraduação em educação da Região Centro-Oeste. Chapada dos Guimarães, fev. 2003.

FOLHA DE S. PAULO. MCT recua na descentralização de recursos para a pesquisa no Brasil. São Paulo, 10 mar. 2004. 
GATTI, B. Mestrados e doutorados: questões de avaliação e políticas de ação. In: A avaliação da pós-graduação em debate. São Paulo: Anped, 1999.

GRUPO Gestor. Por um modelo alternativo de avaliação da pós-graduação nacional. ANPEd-EDUFORUM, mar. 2002.

<http://www.cnpq.br/resultadosjulgamento/062003humanasindice.htm> Acesso em: 20 maio 2004.

<http://www.capes.gov.br> Acesso em: 10 mar. 2004.

PÓS- GRADUAÇÃO: Enfrentando novos desafios. Infocapes. Brasília: Capes, vol. 9, (2 e 3), 2001, p. 5-18.

I PLANO Nacional de Pós-Graduação - 1975. Infocapes. Brasília: Capes, vol. 6, (1), 1998, p. 13-44.

II PLANO Nacional de Pós-Graduação-1982-1985. Infocapes. Brasília: Capes, vol. 6, (2), 1998, p. 20-27.

III PLANO Nacional de Pós-Graduação - 1986-1989. Infocapes. Brasília: Capes, vol. 6, (3), 1998, p. 23-34. 